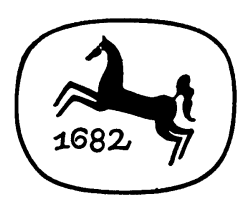

BÜRGERLICH-OPPOSITIONELLE LITERATEN

UND SOZIALDEMOKRatisCHe ARbeIterbeWEgUNG NACH 1890 


\section{Bürgerlich-oppositionelle Literaten und \\ sozialdemokratische Arbeiterbewegung nach 1890}

Die `Friedrichshagener und ihr Einfluß auf die sozialdemokratische Kulturpolitik 
Die Abbildung des Umschlags entnahmen wir dem Buch von Siegfried Nestriepke:

Geschichte der Volksbühne

Berlin, Erster Teil. 1890-1914, Berlin 1930

D 188

ISBN 978-3-476-99602-2 ISBN 978-3-476-99601-5 (eBook)

DOI 10.1007/978-3-476-99601-5

(C) 1974 Springer-Verlag GmbH Deutschland

Ursprünglich erschienen 1974 bei J. B. Metzlersche Verlagsbuchhandlung und Carl Ernst Poeschel Verlag GmbH in Stuttgart 
1. Der allgemeine Rahmen der kulturpolitischen Auseinandersetzungen in den neunziger Jahren: die Arbeiterbildungsbewegung . . . . . . . 1

1.1. Die sozialdemokratische Arbeiterbildung von Liebknechts Rede $>$ Wissen ist Macht, Macht ist Wissen< (1872) bis 1890 . . . . . . . . . 1

1.2. Die bildungspolitische Szenerie der neunziger Jahre . . . . . . . 9

2. Die >Friedrichshagener . . . . . . . . . . . . . . . . . 19

2.1. Der $>$ Friedrichshagener Typus $\triangleleft$. . . . . . . . . . . . . 19

2.2. Literarische Selbstaussagen der >Friedrichshagener $<$. . . . . . . 29

Exkurs: Die öffentliche Diskussion des Begriffs sgeistiges Proletariat< in den Jahren 1890/91 . . . . . . . . . . . . . . . . . . . . . . $\quad .33$

2.3. Politisches Auftreten in der Realgeschichte - die Fraktion der >Jungen $\quad 53$

2.4. Die theoretische Wendung zum Anarchismus . . . . . . . . . 64

3. Die Volksbühne als kulturpolitisches Instrument der >Friedrichshagener und sozialdemokratische Gegenstrategien gegen deren Einflußnahme auf die Arbeiterbewegung . . . . . . . . . . . . . . . . . . 79

3.1. Die >Freie Volksbühne unter der Leitung Bruno Willes bis zur Spaltung der Volksbühnenbewegung (1890-1892) . . . . . . . . . . . 79

Exkurs: Hauptmanns Vor Sonnenaufgang vor der >Freien Volksbühne 96 Exkurs: Ibsens Volksfeind vor der >Freien Volksbühne . . . . . . 99

3.2. Franz Mehring als Hauptgegenspielēr der 'Friedrichshagener und seine Leitungstätigkeit in der $>$ Freien Volksbühne $(1892-1895)$. . . . .

3.3. Das Verhältnis der Sozialdemokratischen Partei zur Volksbühnenbewe-

3.4. Die $>$ Neue Freie Volksbühne< als Theaterorganisation der $>$ Friedrichshagener $(1892-1896)$. . . . . . . . . . . . . . . 133

4. Die Naturalismusdebatte des Gothaer Parteitages von 1896 und ihre Bedeutung für das Verhältnis der Sozialdemokratischen Partei zu den >Friedrichshagenern. . . . . . . . . . . . . . . . . . . . 139

4.1. Grundzüge der Naturalismusdiskussion . . . . . . . . . . . 139

4.2. Die Konzeption Edgar Steigers . . . . . . . . . . . . . . 142

4.3. Hans Lands Roman Der Neue Gott . . . . . . . . . . . . 153

4.4. Wilhelm Hegelers Roman Mutter Bertha . . . . . . . . . 165 
4.5. Die Funktion der Parteitagsdebatte und ihrer Rezeption für das Verhältnis der Sozialdemokratie zu den `Friedrichshagenern . . . . . 182

5. Die Volksbühnenbewegung und der Revisionismus (1897-1902) . . . 195

5.1. Die Wiedergründung der >Freien Volksbühneく 1897 . . . . . . . 196

5.2. Die Revisionisten in der 'Freien Volksbühner und ihr Verhältnis zu den ‘Friedrichshagenern . . . . . . . . . . . . . . 200

6. Ausblick und Fazit . . . . . . . . . . . . . . . . . . . 211

Anmerkungen . . . . . . . . . . . . . . . . . . 219

Literaturverzeichnis . . . . . . . . . . . . . . 261

Personenregister . . . . . . . . . . . . . . . . . . . . 268 